\title{
Weak phenotypic reversion of ivermectin resistance in a field resistant isolate of Haemonchus contortus by verapamil ${ }^{1}$
}

\author{
Fernando A. Borges ${ }^{2 *}$, Julhiano B. Rossini ${ }^{3}$, Patrícia P. Velludo ${ }^{2}$, Carolina \\ Buzzulini $^{2}$, Gustavo H. Costa ${ }^{2}$, Marcelo B. Molento ${ }^{3,4}$ and Alvimar J. Costa ${ }^{2}$
}

\begin{abstract}
Borges F.A., Rossini J.B., Velludo P.P., Buzzulini C., Costa G.H., Molento M.B. \& Costa A.J. 2011. Weak phenotypic reversion of ivermectin resistance in a field resistant isolate of Haemonchus contortus by verapamil. Pesquisa Veterinária Brasileira 31(9):731736. Departamento de Medicina Veterinária, Faculdade de Medicina Veterinária e Zootecnia, Universidade Federal de Mato Grosso do Sul, Campo Grande, MS 79070-900, Brazil. E-mail: fernando.borges@ufms.br

Recent advances in anthelmintic resistant phenotype reversion by Pgp modulating drugs in ruminant nematodes indicate that this can be a useful tool to helminth control. The aim of the present study was to evaluate the efficacy of ivermectin (IVM) in combination with verapamil (VRP), in oil or water-based vehicle, against an IVM-resistant field isolate of Haemonchus contortus through a larval migration assay and experimental infection trial. In the in vitro assay was observed a phenotypic reversion of $H$. contortus resistance to ivermectin at a high concentration of VRP, increasing IVM efficacy from 53.1\% to 94.3. In the in vivo trial, IVM + VRP demonstrated $36.02 \%$ efficacy compared to the $7.75 \%$ of IVM alone. The vehicle formulation showed no influence in efficacy. These are the first results demonstrating the effect of VRP as a partial IVM-resistance phenotype reverser in a field isolate of IVM-resistant $H$. contortus experimentally inoculated in sheep.
\end{abstract}

INDEX TERMS: Haemonchus contortus, ivermectin, P-glycoprotein, resistance, reversion, verapamil.

RESUMO.- [Reversão fenotípica da resistência a ivermectina em isolado de campo de Haemonchus contortus pelo verapamil.] Avanços recentes na reversão fenotípica da resistência anti-helmíntica por drogas moduladoras de Pgp em nematódeos de ruminantes indicam que esta pode ser uma ferramenta útil no controle de helmintos. 0 objetivo do presente estudo foi avaliar a eficácia da ivermectina (IVM), em combinação com o verapamil (VRP), em veículo oleoso ou à base de água, contra um isolado de campo de $H$. contortus resistente por meio de teste de migração de larvas e infecção experimental em ovinos. No teste in vitro, observou-se reversão fenotípi-

\footnotetext{
${ }^{1}$ Received on April 25, 2011.

Accepted for publication on May 6, 2011.

${ }^{2}$ Departamento de Medicina Veterinária, Faculdade de Medicina Veterinária e Zootecnia (Famez), Universidade Federal de Mato Grosso do Sul (UFMS), Campo Grande, MS 79070-900, Brazil. *Corresponding author: fernando.borges@ufms.br

${ }^{3}$ Centro de Pesquisas em Sanidade Animal (Cppar), Faculdade de Ciências Agrárias e Veterinárias (FCAV), Universidade Estadual Paulista (Unesp), Via de Acesso Prof. Paulo Donato Castellane s/n, Jaboticabal, SP 14884900,, Brazil.

${ }^{4}$ Laboratório de Doenças Parasitárias, Universidade Federal do Paraná, Rua dos Funcionários 1540, Cabral, Curitiba, PR 80035-050, Brazil.
}

ca da resistência de Haemonchus contortus à ivermectina com alta concentração de VRP, aumentando a eficácia da IVM de $53,1 \%$ para 94,3 . No teste in vivo, IVM + VRP demonstrou $36,02 \%$ de eficácia em relação a $7,75 \%$ de IVM sozinha. O veículo da formulação não apresentou influência na eficácia. Estes são os primeiros resultados que demonstram o efeito da VRP como reversor parcial do fenótipo da resistência de IVMfenótipo em um isolado de campo de $H$. contortus resistente, inoculado experimentalmente em ovinos.

TERMOS DE INDEXAÇÃO: Haemonchus contortus, ivermectina, Pglycoprotein, resistance, reversion, verapamil

\section{INTRODUCTION}

Macrocyclic lactones (ML) are a third-generation broadspectrum anthelmintic agent for ruminants, but the exact resistance mechanisms are still far from being totally understood. Such mechanisms seem to be polygenic, involving several or many genes (Köhler 2001). Mutations in glutamate-gated chloride $(\mathrm{GluCl})$ receptor genes are associated with ML-resistance (Blackhall et al. 1998), along with mutations in the dye-filling defective (Dyf) genes that encode proteins related to IVM uptake (Dent et al. 2000). The 
first gene associated to ML resistance in Haemonchus contortus was Pgp-A, which encodes a P-glycoprotein, a member of the ATP-binding cassette transporter family (Xu et al. 1998). Pgp homologues are expressed in many organisms, including vertebrates, and are involved in the absorption, distribution, metabolism and excretion processes of xenobiotic compounds (Mealey 2004).

Pgp has been largely studied, as its overexpression can cause drug resistance in human tumor cells due to drug transport from the target cell, resulting in the phenomena known as multidrug resistance (MDR) when several chemical groups are involved (Juliano \& Ling 1976, Gottesman \& Pastan 1993). Pgp is also responsible for MDR in Trypanosoma cruzi and T. brucei brucei, which is a very important protozoan in human and animal health (Kerboeuf et al. 2003).

MDR reversion by modulating drugs is a recent treatment protocol employed in chemotherapy targeting tumor cells. These drugs directly act as competitive inhibitors of Pgpmediated drug efflux and/or through indirect mechanisms that induce an increase in cellular ATP consumption and block the Pgp function (Watanabe et al. 1995, Garrigos et al. 1997). Verapamil (VRP) is a calcium channel blocker (Tsuruo et al. 1981) that has been used with this aim. There are a number of in vitro studies related to Pgp-activity modulation by VRP demonstrating partial reversion to benzimidazole and IVM resistance in nematodes (Beugnet et al. 1997, Molento \& Prichard 1999, 2001, Bartley et al. 2009).

Along with the direct action of resistance reversion, VRP can significantly increase some pharmacokinetic parameters (AUC and Cmax) of co-administrated IVM in sheep, probably due to liver and intestinal Pgp inhibition, thereby reducing biliary excretion and increasing the intestinal absorption of IVM (Molento et al. 2004).

Lespine et al. (2008) pointed that the study of Pgp modulators should follow the following steps: selection of the drug, evaluation of the ability of this drug to modulate Pgp action in cells, pharmacokinetic studies in the host, in vitro tests with resistant parasites and in vivo coadministration of anthelmintic and Pgp modulator on experimentally infected hosts. These authors alerted to some possible problems such as side effects, different pharmacokinetic profile of the anthelmintic and the Pgp modulator, costs and the need of posterior studies on the withdraw period.

Recent studies showed the increase of ivermectin efficacy against resistant nematode in sheep (Lifschitz et al. 2010a) and cattle (Lifschitz et al. 2010b) experimentally infected and also the enhance of ivermectin systemic concentration by the coadministration of loperamide, a Pgp modulator.

All the studies on Pgp modulators in ruminants (Molento et al. 2004, Lifschitz et al. 2010a,b) used the drug diluted in saline solution. The use of a formulation containing the association of a Pgp modulator and ivermectin in an oil-based vehicle could reduce the rate of absorption from the injection site, resulting in prolonged residence time and longer effect of the drug on Pgp modulation.

Considering the absence of studies on Pgp-modulation by verapamil, a classical Pgp inhibitor, in sheep experimentally infected with an IVM-resistant field strain of Haemonchus contortus, the aim of the present study was to evaluate the in vitro and in vivo efficacy of ivermectin co-administered with verapamil and the possible effect of the vehicle formulation.

\section{MATERIALS AND METHODS}

The Ivermectin-resistant field strain of Haemonchus contortus was isolated from the Ovine Sector of the School of Agrarian and Veterinary Sciences, São Paulo State University, Jaboticabal, São Paulo, Brazil. A previous controlled anthelmintic efficacy test following the methodology recommended by Wood et al. (1995) confirmed the extremely high phenotypic resistance status of this field strain of $H$. contortus to IVM, that was ineffective $(-33.97 \%$ efficacy).

For the isolation of the monospecific strain, $H$. contortus females were obtained from abomasums and immediately transferred to a saline solution in Petri dishes at $36^{\circ} \mathrm{C}$ for two hours. The eggs produced were transferred to recipients containing vermiculite and incubated at $27^{\circ} \mathrm{C}$ for 10 days, when the third-stage infective larvae were obtained. Two worm-free sheep were inoculated with 1000 viable L3 larvae and maintained in individual pens at the Animal Health Research Center (CPPAR/Unesp) in order to minimize accidental re-infection.

Infective larvae from an IVM-resistant field strain of $H$. contortus were used in the in vitro agar migration assay test (D'Assonville et al. 1996, modified by Molento \& Prichard, 2001). The larvae were submitted to the following treatments: Group I: 1, 2, 4, 8, 16, 32, 64, 128 and $256 \mu$ M of IVM (ivermectin, Ivomec ${ }^{\circledR}$ Solução Oral, Merial Saúde Animal); Group II: 1, 2, 4, 8, 16, 32, 64, 128 and $256 \mu \mathrm{M}$ of IVM co-administrated with $2 \mathrm{mM}$ of VRP (verapamil hydrochloride, Sigma, St Luis, Missouri, USA) - this concentration of VRP showed to be able to increase the efficacy of IVM in other work (Molento \& Prichard 2001); Group III: 1, 2, 5, 10 and 100mM of VRP; Group IV: IVM EC ${ }_{50}$ co-administrated with $0,1,2,5,10$ and $100 \mathrm{mM}$ of VRP.

The drugs were diluted in distilled water, instead of oil to avoid interference in the larvae migration in agar, and vortexed immediately prior to use. In each experimental group, there was a triplicate that only received distilled water, used as the control group. The larva number used in each of the four groups was variable, depending on the availability. Thus, efficacy percentages between treatments were statistically compared rather than mean larva survival rate.

The in vivo evaluation of reversion of ivermectin resistance design and procedures were performed based on the guidelines of the WAAVP (Wood et al. 1995) and VICH (Vercruysse et al. 2001). The management of the experimental sheep was carried out in compliance with the Ethics Committee of the institution and "Good Clinical Practice" guidelines (VICH GL9, 2000, http:// vich.eudra.org/pdf/2000/GL09_st7.pdf).

As it was not possible to produce a large number of naive animals, the decision was made to use lambs that were treated with an anthelmintic agent until the total elimination of any pre-experimental nematode infection. All animals were housed in stalls designed to avoid parasitic infections and provided with daily food and water ad libitum.

After an acclimation period, each worm-free animal was orally inoculated with 8460 IVM-resistant $H$. contortus L3 larvae. Thirty of the 35 inoculated sheep were selected based on eggs per gram (EPG) counts on Days 32, 33 and 34 post-inoculation. The animals were ranked based on the EPG count and allocated into five groups $(n=6)$ in a randomized block design: I- Control; II- 1\% IVM (200 $\mu \mathrm{g} / \mathrm{kg}$ ); III- 15\% VRP ( $3 \mathrm{mg} / \mathrm{kg}$ ), water-based vehicle, administrated three times at 12-hour intervals; IV- 1\% IVM (200 $\mu \mathrm{g} / \mathrm{kg})$, single dose, co-administered with 15\% VRP (3mg/kg), water-based vehicle, administrated three times at 12-hour intervals (separate formulations); V- $1 \%$ IVM $(200 \mu \mathrm{g} / \mathrm{kg}$ ) plus $15 \% \mathrm{VRP}(3 \mathrm{mg} / \mathrm{kg})$, 
oil-based vehicle (sterile pure corn oil), single dose (combined formulation).

All treatments were performed subcutaneously on Day 35 postinoculation and the animals were observed for possible adverse reactions. The established VRP dose of $3 \mathrm{mg} / \mathrm{kg}$ is the safest for sheep when diluted in saline solution and administered subcutaneously (Molento et al. 2004). The aim of using an oil-based vehicle is to allow slow absorption of the drug from the injection site, as VRP is absorbed and eliminated very quickly, whereas macrocyclic lactones have a longer absorption half-life and mean residence time.

All sheep were sacrificed seven days post-treatment and subjected to a parasitological necropsy in order to determine the worm burden. Fecal samples were collected and eggs per gram (EPG) were determined for each animal (Gordon \& Whitlock 1939) in order to evaluate the effect of the treatments on nematode reproduction.

The half maximal effective concentration $\left(\mathrm{EC}_{50}\right)$ of IVM against the resistant field strain was calculated using the GraphPad Prism software program (GraphPad Prism, version 5.01 for Windows, San Diego, California, USA, www.graphpad.com). The total number of surviving larvae in each treatment was log-transformed and normalized to fit a dose-response sigmoid curve. The curves were statistically compared (fitted values log EC50 and Hill slope) by the Tukey's multiple comparison test. The total $H$. contortus number recovered at the necropsy of each animal was transformed in log $x+1$. The therapeutic efficacy of the formulations was calculated based on the method described by Wood et al. (1995). The fecal egg count reduction (FECR) was calculated based on the guidelines of the US Food and Agriculture Organization (FAO 2004): FECR \% $=[1-(C 1 / C 2) \times(T 2 / T 1)] \times 100$, in which $\mathrm{T}$ and $\mathrm{C}$ are the geometric means for the treated and control groups and subscripts 1 and 2 designate the counts before and after treatment, respectively. In the controlled anthelmintic test, the D'Agostino-Pearson normality test was used to quantify how far the distribution is from Gaussian in terms of asymmetry and shape. The data were transformed and one-way analysis of variance (ANOVA) with Tukey's Multiple Comparison post hoc test was performed on the log-transformed data.

\section{RESULTS}

The in vitro test results of IVM alone and associated to VRP are displayed in Figure 1 and 2. Table 1 displays the total number of surviving larvae exposed to VRP alone and its association with $\mathrm{EC}_{50}$ IVM as well as the efficacy of the drugs.

The IVM sigmoid dose-response curve was not statistically significantly $(\mathrm{P}>0,05)$ different from IVM associated to VRP $(2 \mathrm{mM})$ (Fig.1). The $\mathrm{EC}_{50}$ for IVM alone was $4.314 \mu \mathrm{M}$, with a $95 \%$ confidence interval ranging from 3.045 to $5.900 \mu \mathrm{M}$,

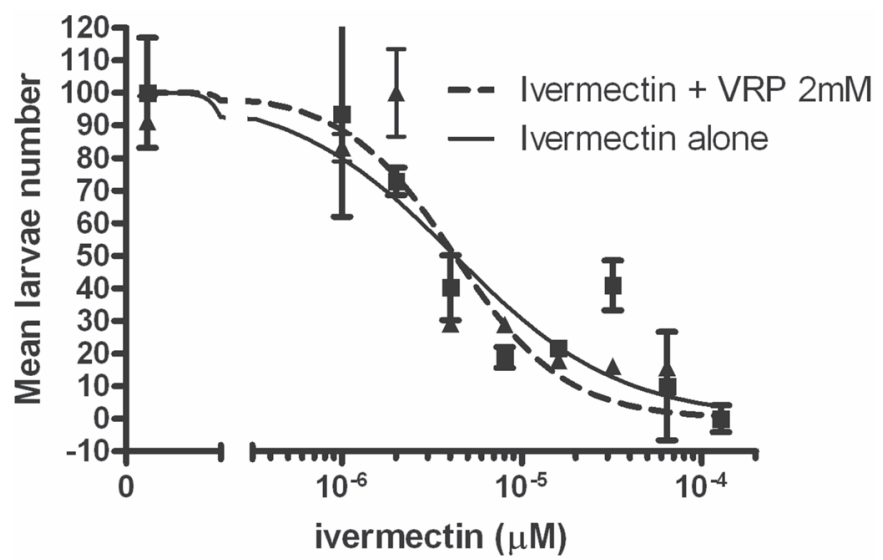

Fig.1. In vitro agar migration assay test results. Dose-response sigmoid curve of IVM alone and IVM associated with VRP (2 $\mathrm{mM}$ ) against IVM-resistant field isolate of Haemonchus contortus (normalized-transformed data)

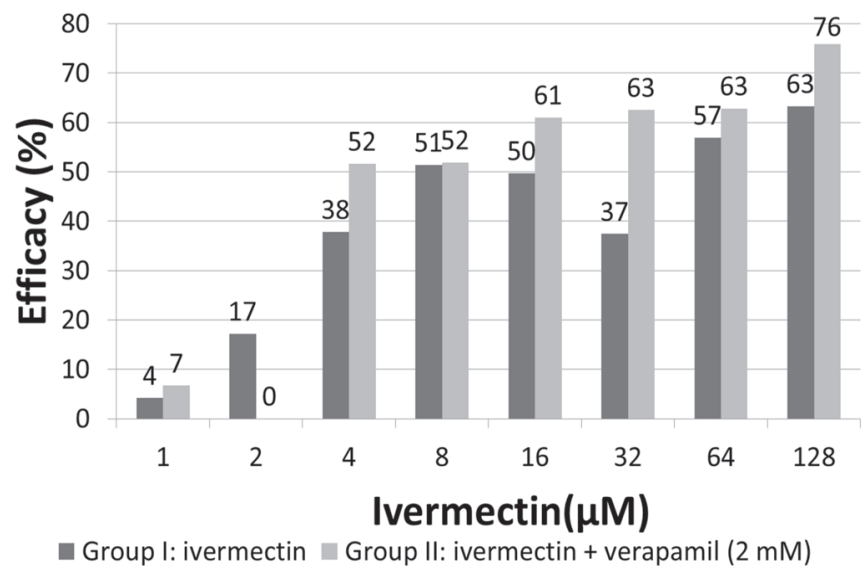

Fig.2. In vitro agar migration assay test results. Efficacy (\%) of IVM alone and IVM associated with VRP (2 mM) against IVMresistant field isolate of Haemonchus contortus

compared to 3.045ìM for IVM plus VRP (2mM), ranging from 3.047 to $5.898 \mu \mathrm{M}(95 \%$ confidence interval).

The presence of VRP $(2 \mathrm{mM})$ did not reduced $(\mathrm{P}=0.074)$ the number of surviving larvae, although it was observed greater efficacy of IVM associated with VRP (Fig.2), except at the dilution of $2 \mu \mathrm{M} / 0.5 \mathrm{~mL}$ (Fig.2). The efficacy of $128 \mathrm{iM}$ of IVM plus $2 \mathrm{mM}$ of VRP was $12.55 \%$ higher than $128 \mu \mathrm{M}$ of IVM alone.

Table1. In vitro agar migration assay test results, mean number of surviving Haemonchus contortus larvae, and efficacy of VRP alone (Group III) and associated with IVM EC ${ }_{50}$ (Group IV)

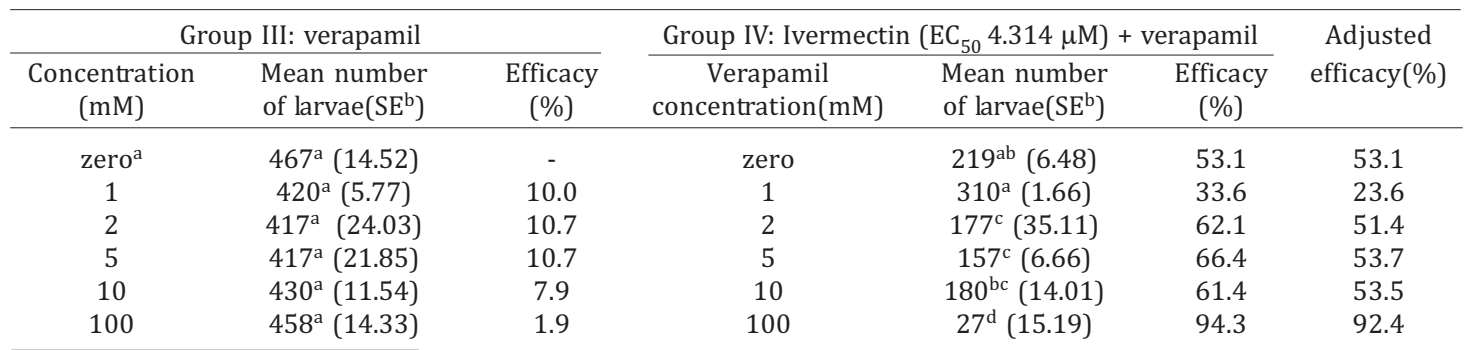

${ }^{*}$ Control triplicates $=$ larvae were treated with distilled water alone. ${ }^{* *} \mathrm{SE}=$ Standard error. ${ }^{* * *}$ Adjusted efficacy $=$ efficacy of group IV - efficacy of group III. ${ }^{\mathrm{a}, \mathrm{b}, \mathrm{c}, \mathrm{d}}=$ mean values in the same column followed by at least one common letter do not differ by Tukey's multiple comparison test $(\mathrm{P}>0,05)$. 
Table 2. In vivo results. Geometric means of EPG counts and number of adult Haemonchus contortus recovered at necropsy

\begin{tabular}{|c|c|c|c|c|c|c|}
\hline \multirow[t]{2}{*}{ Treatment } & & \multicolumn{2}{|c|}{$\mathrm{EPG}$} & \multicolumn{3}{|c|}{ H. contortus } \\
\hline & & D zero & $\mathrm{D}+7$ & Male & Female & Total \\
\hline Control & Mean & 3520 & 7240 & 451 & 546 & 1016 \\
\hline verapamil & Mean & 3533 & 11576 & 480 & 597 & 1087 \\
\hline $3 \mathrm{mg} / \mathrm{kg}(\mathrm{aq})$. & Efficacy & - & $0.00 \%$ & $0.00 \%$ & $0.00 \%$ & $0.00 \%$ \\
\hline ivermectin & Mean & 3533 & 8166 & 408 & 506 & 937 \\
\hline $200 \mu \mathrm{g} / \mathrm{kg}$ & Efficacy & - & $0.00 \%$ & $9.43 \%$ & $7.26 \%$ & $7.75 \%$ \\
\hline ivermectin $200 \mu \mathrm{g} / \mathrm{kg}+$ & Mean & 3415 & 10006 & 316 & 316 & 650 \\
\hline verapamil 3mg/kg (aq.) & Efficacy & - & $0.00 \%$ & $29.89 \%$ & $42.15 \%$ & $36.02 \%$ \\
\hline ivermectin $200 \mu \mathrm{g} / \mathrm{kg}+$ & Mean & 3585 & 6165 & 415 & 566 & 995 \\
\hline verapamil 3mg/kg (oil) & Efficacy & - & $16.39 \%$ & $7.97 \%$ & $0.00 \%$ & $2.14 \%$ \\
\hline One-way ANOVA; Significant & & & 0.86 & & & 0.94 \\
\hline P-value $(\mathrm{P}<0.05)$ & & & No & & & No \\
\hline
\end{tabular}

VRP administrated alone had no action against nematode parasites (Table 1), even at high concentrations (100mM). However, increasing concentrations of VRP associated to IVM $\mathrm{EC}_{50}$ resulted in an increase in IVM efficacy against the resistant H. contortus isolate (Table 1). IVM ( $\mathrm{EC}_{50}$ ) associated to 2,5 or $100 \mathrm{mM}$ of VRP caused a significant reduction in the number of larvae $(\mathrm{P}<0.05)$ when compared to IVM $\mathrm{EC}_{50}$ alone. IVM $\left(\mathrm{EC}_{50}\right)$ associated to $100 \mathrm{mM}$ of VRP showed $94.3 \%$ efficacy against the resistant H.contortus isolate, while IVM (EC50) alone caused the mortality of $53.1 \%$ of the larvae, as expected. To exclude possible direct verapamil effect on Haemonchus contortus, it was calculated the adjusted efficacy (efficacy of IVM plus VRP - efficacy of VRP alone) shown on Table 1.

No local or systemic adverse reactions were observed in the sheep following VRP administration. The in vitro results revealed that VRP administered alone, at 1, 2, 5, 10 and $100 \mathrm{mM}$, had no anthelmintic effect.

The FECR results (Table 2) revealed an increase in the number of $H$. contortus eggs eliminated in the feces of all animals in comparison to Day 0 (prior to treatment). The $1 \%$ IVM + 15\% VRP (oil-based vehicle) treatment demonstrated limited efficacy (16.39\%) in the reduction of EPG, but the mean egg number was not statistically different from the control group $(\mathrm{P}>0.05)$. The other treatments had no efficacy with regard to FECR.

The controlled anthelmintic test results demonstrated no efficacy of the IVM, thereby confirming the resistant phenotype status of this $\mathrm{H}$. contortus isolate (Table 2). The FECR and the controlled test results were similar, except for $1 \%$ IVM $(200 \mu \mathrm{g} / \mathrm{kg})$, single dose, co-administered with $15 \%$ VRP $(3 \mathrm{mg} / \mathrm{kg}$ ) (water-based vehicle), administrated three times at 12-hour intervals (separate formulations), which demonstrated a general efficacy of $36.02 \%$ (29.89\% against H. contortus males and $42.15 \%$ against females). This value was 4.65 -fold higher than IVM alone (7.75\%), thereby demonstrating a partial reversion of resistance. One percent IVM ( $200 \mu \mathrm{g} / \mathrm{kg}$ ) plus $15 \%$ VRP (3mg/kg) (oil-based vehicle) in a combined formulation had no efficacy against this resistant $H$. contortus isolate, as there were a high number of post-treatment parasites.

\section{DISCUSSION}

The in vitro agar gel larva migration assay was a practical, inexpensive, fast, quantitative method for assessing anthel- mintic efficacy and could be an important tool for determining anthelmintic resistance in nematodes found in ruminants. Using the same methodology, but a laboratory-selected isolate, Molento \& Prichard (2001) observed different results to the present work. Fifty-five percent efficacy was found for IVM alone and $84 \%$ for IVM associated with $2 \mathrm{mM}$ of VRP. In the present study, this concentration of verapamil was not sufficient to increase the efficacy of IVM and only high VRP levels $(100 \mathrm{mM})$ could increase IVM from $53.1 \%$ to $94.3 \%$. It is an interesting result, since the same methodology, nematode specie and drug concentrations were used, remarkable differences in efficacy were observed.

Partial reversion of the resistance of Haemonchus contortus to another chemical group (benzimidazole) occurred in an egg hatch test involving both resistant and susceptible isolates, for which VRP caused an increase in efficacy of thiabendazole and albendazole $\mathrm{EC}_{50}$, with more visible action in resistant rather than susceptible isolates (Beugnet et al. 1997). Other in vitro study demonstrated the action of a different Pgp modulator. Prior exposure of $H$. contortus eggs to lectin resulted in a thiabendazole $\mathrm{EC}_{50}$ reduction of $50.9 \%$ in a susceptible isolate and $47.2 \%$ and only $27.4 \%$ against two resistant isolates.

There are only a few studies that have tested the effect of Pgp modulators for increasing the anthelmintic efficacy in animal hosts infected by $H$. contortus. In one experiment conducted in Brazil, VRP associated to IVM was evaluated in naturally infected sheep and $74.71 \%$ efficacy was observed, while IVM alone demonstrated no efficacy (Borges et al. 2005). Molento \& Prichard (1999) used an experimental model with jirds (Meriones unguiculatus) infected with an IVM-resistant $H$. contortus isolate and found $26 \%$ efficacy with IVM alone and $48 \%$ when associated with VRP. In the same experimental model, Xu et al. (1998) used a H. contortus isolate selected with moxidectin and observed $80 \%$ and $70 \%$ efficacy of IVM and moxidectin when administrated alone and $90 \%$ and $96 \%$ efficacy when associated to VRP, respectively. The VRP dose was much higher in the latter experiment $(20 \mathrm{mg} / \mathrm{kg})$ than in the present work $(3 \mathrm{mg} / \mathrm{kg})$.

The first anthelmintic controlled tests with experimentally infected ruminants were carried out by Lifschitz et al. (2010a) in sheep and Lifschitz et al. (2010b) in cattle. Loperamide increased the efficacy of IVM from 23 to $50 \%$ and of moxidectin from 69 to $87 \%$ against a resistant Cooperia 
oncophora isolate in cattle and the efficacy of IVM from $0 \%$ to $72.5 \%$ against $H$. contortus in sheep.

These results are different from the observed in the present study. Co-administered VRP and IVM in a combined formulation with oil-based vehicle caused no increase in IVM anthelmintic efficacy against the IVM-resistant $H$. contortus isolate, as there were a large number of parasites in the animals with this treatment. These results show the influence of the formulation over anthelmintic efficacy, as the same compounds in water-based vehicle achieved satisfactory results. It was expected that the oil vehicle formulation would show higher efficacy because it would allow a slow absorption of VRP and consequently more long-acting modulation of Pgp. until IVM could achieve the peak plasma concentration. Future studies on the pharmacokinetics of the VRP and IVM formulation in sheep will help answer questions regarding the vehicle and drug concentrations.

It was observed a remarkable difference between the FECRT and the anthelmintic controlled test, especially in the treatment IVM (200 ìg $/ \mathrm{kg}$ ) plus $15 \%$ VRP (3 mg/kg) in waterbased vehicle. In FECRT, this group showed $0 \%$ efficacy while in the anthelmintic controlled test it was observed efficacy of $36.02 \%$. According to Coles et al (2006), the anthelmintic controlled test controlled efficacy test is the most reliable method and is considered the gold standard for detecting anthelmintic resistance. FECRT can be affected by the fecundity of the female worms due to density-related modulation of egg output by female, as described by Koop e $t$ al. (2008) in Ancylostoma caninum. these authors observed that egg counts in the treated dogs were $41 \%$ higher 6 days after treatment, despite the killing of $71 \%$ of the adult worms.

Pouliot et al. (1997) evaluated the hydrophobicity of ivermectin and VRP and MDR reversion and found ivermectin to be nine-fold more hydrophobic than VRP; consequently, ivermectin was found to be a better inhibitor of drug transport by Pgp. The structure/affinity relationship for the interaction between Pgp and macrocyclic lactones (ivermectin, abamectin, eprinomectin, doramectin, selamectin and moxidectin) and the Pgp inhibitors valspodar and VRP was evaluated by Lespine et al. (2007), who found a considerable variation in the transport rate of the drugs by Pgp. IVM was a 10 -fold and 7.23-fold more potent substrate of Pgp than moxidectin and VRP, respectively. These results show that IVM has greater affinity and is extensively more transported by Pgp than VRP. Thus, it is expected that VRP would not be the best Pgp modulator for IVM-resistance reversion in $H$. contortus as demonstrated by Bartley et al. (2009) that used a cell culture model test and observed that there are significant differences between the concentrations of ivermectin, ketoconazole, quercetin, pluronic P85, valspodar and verapamil to inhibit the Pgp transport activity. In addition, verapamil showed to be a better Pgp modulator than ketoconazole but a least potent Pgp inhibitor than valspodar, ivermectin and pluronic P85 in a larval feeding inhibition test with resistant isolates of Teladorsagia circumcincta and H. contortus.

Although verapamil showed to be a potent Pgp modulator in previous studies (Beugnet et al. 1997, Molento \& Prichard 1999, Bartley et al. 2009) it was not efficient in reverting the phenotype in the $H$. contortus isolate evaluated in the present work. These are the first results demonstrating the effect of VRP as a partial IVM-resistance phenotype reverser in a field isolate of IVM-resistant $\mathrm{H}$. contortus experimentally inoculated in sheep. The study of the physiochemical properties of Pgp drug modulators may reveal molecules with a greater binding and transport rate than IVM, resulting in better Pgp inhibition and, consequently, higher anthelminticresistance phenotype reversion than that observed for VRP in the present experiment and by other authors.

Acknowledgments.- To Dr. Johanna Martha Kopte (in memoriam) for the pharmacological preparations. Funding for this work was provided by FAPESP (Proc.04/12803-1).

\section{REFERENCES}

Bartley D.J., McAllister H., Bartley Y., Dupuy J., Ménez C., Alvinerie M., Jackson F. \& Lespine A. 2009. P-glycoprotein interfering agents potentiate ivermectin susceptibility in ivermectin sensitive and resistant isolates of Teladorsagia circumcincta and Haemonchus contortus. Parasitology 136(9):1081-1088.

Beugnet F., Gauthey M. \& Kerbouef D. 1997. Partial in vitro reversal of benzimidazole resistance by the free-living stages of Haemonchus contortus with verapamil. Vet. Rec. 29:575-576.

Blackhall W.J., Pouliot J.F., Prichard R.K. \& Beech R.N. 1998. Haemonchus contortus: Selection at a glutamate-gated chloride channel gene in ivermectin and moxidectin-selected strains. Exp. Parasitol. 90:42-48.

Borges F.A., Silva H.C., Buzzolini C., Soares V.E., Costa A.J. \& Molento M.B. 2005. Use of verapamil to increase anthelmintic efficacy of ivermectin against drug-selected strain of Haemonchus contortus. Proc. $20^{\text {th }}$ International Conference of the World Association for the Advancement of Veterinary Parasitology, Christchurch, New Zealand, p.73.

Coles G.C., Jackson F., Pomroy W.E., Prichard R.K., Samson-Himmelstjerna G. von, Silvestre A., Taylor M.A. \& Vercruysse J. 2006. The detection of anthelmintic resistance in nematodes of veterinary importance. Vet. Parasitol. 136:167-185.r

D’Assonville J.A., Janovsky E. \& Verster A. 1996. In vitro screening of Haemonchus contortus third stage larvae for ivemectin resistance. Vet. Parasitol. 61:73-80.

Dent J.A., Smith M., Vassilatis D. \& Avery L. 2000. The genetics of ivermectin resistance in Caenorhabditis elegans. Proc. Natl Acad. Sci. USA 97:26742679.

FAO 2004. Module 2. Helminths: Anthelmintic resistance, diagnosis, management and prevention. Guidelines Resistance Management and Integrated Parasite Control in Ruminants. FAO, Roma, p.78-118.

Garrigos M., Mir L.M. \& Orlowski S. 1997. Competitive and non-competitive inhibition of the multidrug-resistance-associated P-glycoprotein ATPase: Further experimental evidence for a multisite model. Eur. J. Biochem. 244:664-673.

Gordon H.M. \& Whitlock H.V. 1939. A new technique for counting nematode eggs in sheep faeces. J. Counc. Sci. Ind. Res. Aust. 12:50-52.

Gottesman M.M. \& Pastan I. 1993. Biochemistry of multidrug resistance mediated by the multidrug transporter. Annu. Rev. Biochem. 62:385-427.

Juliano .R.L. \& Ling V. 1976 A surface plycoprotein modulating drug permeability in Chinese hamster ovary cell mutants. Biochem. Biophys. Acta 455:152-162.

Kerboeuf D., Blackhall W., Kaminsky R. \& Samson-Himmelstjerna G.V. 2003. P-glycoprotein in helminthes: Function and perspectives for anthelmintic treatment and reversal of resistance. Int. J. Parasitol. 22:332-346.

Köhler P. 2001 The biochemical basis of anthelmintic action and resistance. Int. J. Parasitol. 31:336-345.

Kopp S.R., Coleman G.T., McCarthy J.S. \& Kotze A.C. 2008. Application of in vitro anthelmintic sensitivity assays to canine parasitology: Detecting resistance to pyrantel in Ancylostoma caninum. Vet. Parasitol. 152:284293. 
Lespine A., Martin S., Dupuy J., Roulet A., Pineau T., Orlowski S. \& Alvinerie M. 2007. Interaction of macrocyclic lactones with p-glycoprotein: Structure-affinity relationship. Eur. J. Pharm. Sci. 30:84-94.

Lifschitz A., Entrocasso C., Alvarez L., Lloberas M., Ballent M., Manazza G., Virkel G., Borda B. \& Lanusse C. 2010. Interference with P-glycoprotein improves ivermectin activity against adult resistant nematodes in sheep. Vet. Parasitol. 172(3/4):291-298.

Lifschitz A., Suarez V.H., Sallovitz J., Cristel S.L., Imperiale F., Ahoussou S., Schiavi C. \& Lanusse C. 2010b. Cattle nematodes resistant to macrocyclic lactones: Comparative effects of P-glycoprotein modulation on the efficacy and disposition kinetics of ivermectin and moxidectin. Exp. Parasitol. 125:172-178.

Mealey K.L. 2004. Therapeutic implications of the MDR-1 gene. J. Vet. Pharmacol. Ther. 27:257-264.

Molento M.B., Lifschitz A., Sallovitz J., Lanusse C. \& Prichard R. 2004. Influence of verapamil on the pharmacokinetics of the antiparasitic drugs ivermectin and moxidectin in sheep. Parasitol. Res. 92:121-127.

Molento M.B. \& Prichard R.K. 1999. Effects of the multidrug-resistancereversing agents verapamil and CL 347,099 on the efficacy of ivermectin or moxidectin against unselected and drug-selected strains of Haemonchus contortus is jirds (Meriones unguiculatus). Parasitol. Res. 85:10071011.

Molento M.B. \& Prichard R.K. 2001 Effect of multidrug resistance modulators on the activity of ivermectin and moxidectin against selected strains of Haemonchus contortus infective larvae. Pesq. Vet. Bras. 21:117121.

Pouliot J.F., L'heureux F., Liu Z., Prichard R.K. \& Georges E. 1997 Reversal of P-glycoprotein-associated multidrug resistance by ivermectin. Biochem. Pharmacol. 53:17-25.

Tsuruo T., Lida H., Tsukagoshi S. \& Sakurai Y. 1981. Overcoming of vincristine resistance in P388 leukemia in vivo and through enhenced cytotoxicity of vincristine and vinblastine by verapamil. Cancer Res. 41:1967-1972.

Vercruysse J., Holdsworth P., Letonja T., Barth D., Conder G., Hamamoto K. \& Okano K. 2001 International Harmonisation of Anthelmintic Efficacy Guidelines. Vet. Parasitol. 96:171-193.

Watanable T., Tsuge H., Oh-Hara T., Naito M. \& Tsuruo T. 1995 Comparative study on reversal efficacy of SDZ PSC 833, cyclosporin A and verapamil on multidrug resistance in vivo. Acta Oncol. 34:235-241.

Wood I.B., Amaral N.K., Bairden K., Duncan J.L., Kassai T., Malone J.B., Pankavich J.A., Reinecke R.K., Slocombe O., Taylor S.M. \& Vercruysse J. 1995. World Association for the Advancement of Veterinary Parasitology (WAAVP) Second edition of guidelines for evaluating the efficacy of anthelmintics in ruminants (bovine, ovine, caprine). Vet. Parasitol. 58:181-213.

Xu Ming., Molento M., Blackhall W., Ribeiro P., Beech R. \& Prichard R. 1998. Ivermectin resistance in nematodes may be caused by alteration of Pglycoprotein homolog. Mol. Biochem. Parasitol. 91:327-335. 